\title{
Laparoscopic Excision of Subdiaphragmatic Epidermoid Cyst: A Case Report
}

\author{
By A. Hagr, J.-M. Laberge, L.T. Nguyen, S. Emil, C. Bernard, and Y. Patenaude \\ Montreal, Quebec
}

Retroperitoneal epidermoid cysts are rare. The authors report a case of an 11-year-old boy with an asymptomatic subdiaphragmatic cyst, which was found incidentally during an investigation for hypertension. At laparoscopy, the cyst was densely adherent to the diaphragm, resulting in a pneumothorax during dissection. Nevertheless, the excision and the diaphragmatic repair could be completed laparo- scopically without complication. Microscopic examination showed an epidermoid cyst. No similar case has been reported in the literature.

J Pediatr Surg 36:E8. Copyright $\odot 2001$ by W.B. Saunders Company.

INDEX WORDS: Diaphragm, epidermoid, cyst, laparoscope.
$\mathbf{N}$ ONCUTANEOUS epidermoid cysts are uncommon anomalies that can be found anywhere in the body. Splenic epidermoid cysts are well known to pediatric surgeons, ${ }^{1}$ radiologists, and pathologists, but a diaphragmatic one has not been reported. We report an isolated asymptomatic diaphragmatic epidermoid cyst in an 11year-old boy.

\section{CASE REPORT}

An 11-year-old boy was investigated for headache and hypertension. He had no significant past medical history and an unremarkable physical examination except for blood pressure ranging from 160/90 to $120 / 65$. Laboratory investigation for hypertension was negative. An abdominal ultrasound scan showed an anechoic lesion measuring $4 \times$ $3 \times 4 \mathrm{~cm}$ adjacent to the lateral and posterior part of spleen, suggestive of splenic cyst versus retroperitoneal cyst. Abdominal computed tomography confirmed the presence of a well-defined thin-walled homo-

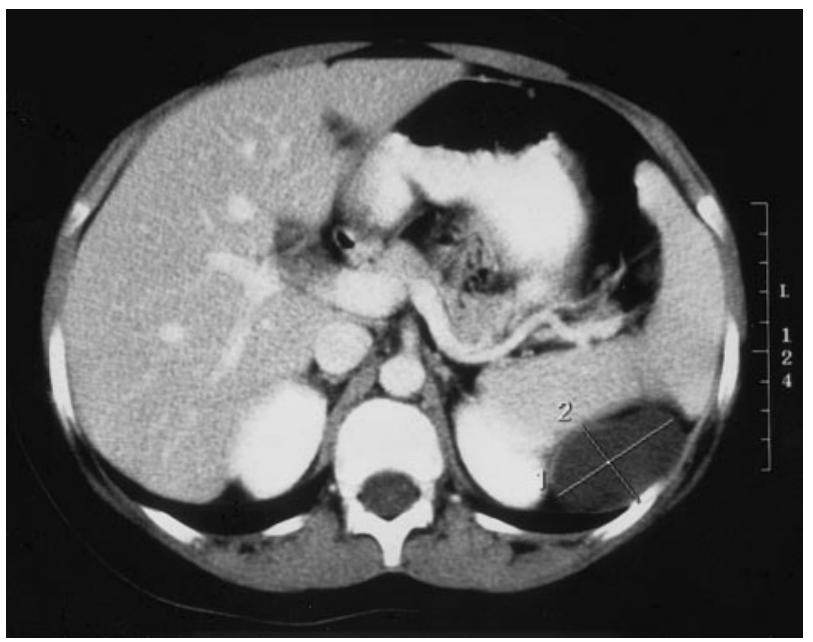

Fig 1. Well-defined, thin-walled homogenous cyst measuring $3.5 \times 3 \times 3 \mathrm{~cm}$. geneous cyst in the left upper retroperitoneal area without signs of inflammation in the surrounding fat (Fig 1).

There was no clear connection with any surrounding organs. The remainder of the examination was normal. His hypertension disappeared gradually, and he was weaned off medication. Because this cyst appeared to be an incidental finding, the patient was observed initially.

After 3 months, he started to complain of nonspecific abdominal pain. Repeated ultrasound scan and computed tomography findings were unchanged. Because the origin and nature of the cyst was not clear, the patient underwent laparoscopic cyst excision. At laparoscopy, the cyst was found to be adherent only to the diaphragmatic muscle. During excision, a 1-cm diaphragmatic perforation occurred, the insufflating pressure was decreased, and the positive end-expiratory pressure was increased by the anesthetist. The procedure was completed laparoscopically, and the small diaphragmatic perforation was closed with interrupted sutures while the anesthetist maintained a positive pressure. The postoperative chest x-ray did not show any significant pneumothorax, so a chest tube was not inserted. The patient was discharged home the next day after an uneventful recovery. He remains well after 6 months, without any recurrence of his hypertension.

Histopathologic examination showed a cyst to be lined with squamous stratified epithelium. The wall of the cyst consisted of dense fibrous tissue with focal dystrophic calcifications. In the surrounding tissue, there was fibroadipose tissue and a thin layer of striated muscle from the diaphragm (Fig 2). There was no evidence of malignancy on the examined material nor features suggesting a dermoid cyst, teratoma, or bronchogenic cyst. Based on histologic features, the lesion was diagnosed as an epidermoid cyst.

From the Services of Pediatric General Surgery, Pathology, and Radiology, The Montreal Children's Hospital, McGill University Health Center, Montreal, Quebec, Canada.

Address reprint requests to J.-M. Laberge, MD, FRCS(C), FACS, Department of Pediatric General Surgery, The Montreal Children's Hospital, 2300 Tupper St, Room C-1137, Montreal, Quebec, Canada H3H 1 P3.

Copyright C 2001 by W.B. Saunders Company

1531-5037/01/3606-0046\$35.00/0

doi:10.1053/jpsu.2001.24021 

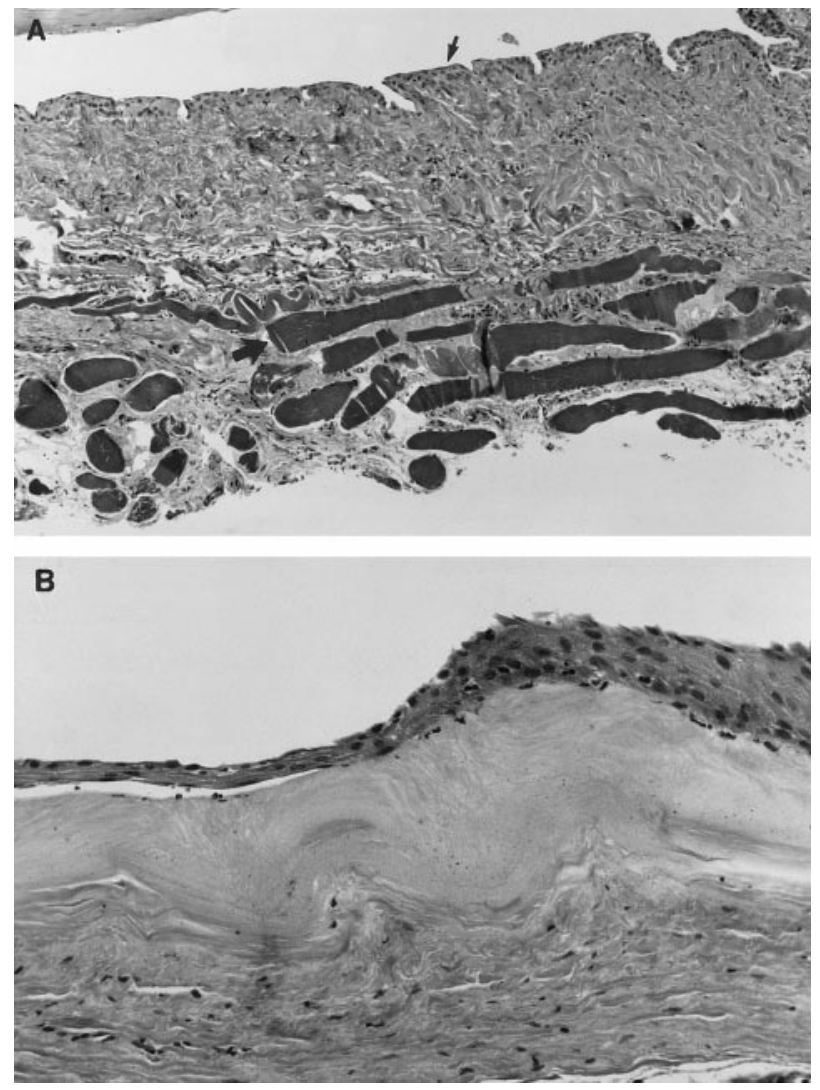

Fig 2. (A) Cyst lined with benign squamous epithelium (small arrow) and a thin layer of striated muscle (large arrow). (H\&E original magnification $\times 100$.) (B) Close view of the stratified epithelium without atypia or inflammatory changes. (H\&E original magnification $\times 400$.)

\section{DISCUSSION}

Epidermoid cysts are true cysts. The lining of these common benign tumors consists of a stratified squamous epithelium that resembles that of normal epidermis but lacking skin appendages, which are present in dermoid cyst. This lining produces fully matured, keratinized cellular debris, which fill the cavity of the cyst. Retroperitoneal cysts are extremely rare entities. They usually are discovered incidentally during investigation of irrelevant illnesses or during routine abdominal ultrasound scan, for example, during pregnancy. ${ }^{2}$ In this area, the site of origin sometimes is very difficult to identify. Bronchogenic cysts, hydatid cysts, and splenic cysts have been reported. Epidermoid cysts in this area are very rare and usually arise from the spleen. ${ }^{3-6}$ To our knowledge, epidermoid cysts arising from the diaphragm have not been reported in the literature since 1960. Recently, an intradiaphragmatic bronchogenic cyst was reported in a 51-year-old patient. $^{5}$

Epidermoid cysts may become symptomatic, causing flank pain, acute abdomen, and they may become infected or rupture ${ }^{7-9}$ as illustrated in a review of 159 cases of epidermoid cysts of the spleen since 1929. In our patient, the cyst certainly did not cause the hypertension and was not the likely cause of vague abdominal pain. Nevertheless, we feel that resection was indicated to establish a diagnosis and prevent future complications.

\section{REFERENCES}

1. Gittes GT: Lesion of the pancreas and spleen, in Ashcaft KW (ed): Pediatric Surgery (ed 3). Philadelphia, PA, Saunders, 2000, p 632

2. Bar-Zohar D, Sherer Y, Manor H, et al: Epidermoid cyst of the spleen. Harefuah 134:182-185, 1998

3. Abu-Eshy SA: Some rare presentations of hydatid cyst (Echinococcus granulosus). J Roy Coll Surg Ed 43:347-352, 1998

4. Ross ME, Elwood R, Yang SS, et al: Epidermoid splenic cysts. Arch Surg 112:596-599, 1977

5. Hoang C, Aubriot MH, Totobenazara JL, et al: Isolated retroperitoneal intradiaphragmatic bronchogenic cyst. A case report. Clin Exp Pathol 47:67-70, 1999
6. Itoh $\mathrm{H}$, Shitamura $\mathrm{T}$, Kataoka $\mathrm{H}$, et al: Retroperitoneal bronchogenic cyst: Report of a case and literature review. Pathol Int 49:152155, 1999

7. Spencer NJ, Arthur RJ, Stringer MD: Ruptured splenic epidermoid cyst: Case report and imaging appearances. Pediatr Radiol 26: 871-873, 1996

8. Didlake RH, Miller RC: Epidermoid cyst of the spleen manifested as an abdominal abscess. South Med J 79:635-637, 1986

9. Panossian DH, Wang N, Reeves CD, et al: Epidermoid cyst of the spleen presenting as a generalized peritonitis. Am Surg 56:295-298, 1990 